\title{
Heterotopic brain tissue in the sacrococcygeal region
}

\author{
W D P Sugathadasa ${ }^{1}$, N V Ratnatunga ${ }^{1}$, K S U Kiriwattuduwe ${ }^{2}$, P H Ariyawanse ${ }^{3}$
}

Ceylon Medical Journal 2013; 58: 126-128

\section{Introduction}

The sacrococcygeal region is the seat of frequent developmental anomalies and a favoured site for germ cell tumours in the paediatric age group.We report an unusual case of heterotopic brain tissue mimicking a teratoma in a neonate. To the best of our knowledge, this is the first such report.

\section{Case report}

A new born baby girl was found to have a skin covered lesion in the right buttock. She was otherwise normal and had no demonstrable neurological deficits. There was no change in tension in the lump with crying.

Computerised tomography (CT) of pelvis and buttocks revealed a large mass with an irregular outline, measuring $7 \mathrm{~cm} \times 4.3 \mathrm{~cm}$. The lesion contained a few areas of calcification and nonenhancing cystic areas. A lower sacral spina bifida was also noted. There was a soft tissue component within the spinal canal of the lower sacral segment. The bladder was compressed upwards by the lesion (Figure 1). Serum alpha fetoprotein level of the baby was $31,037.0 \mathrm{IU} / \mathrm{ml}$ or $37,393.98 \mathrm{ng} / \mathrm{ml}$ (reference value for term neonates - 34,600.21 IU/ml or 41,687 ng/ml).

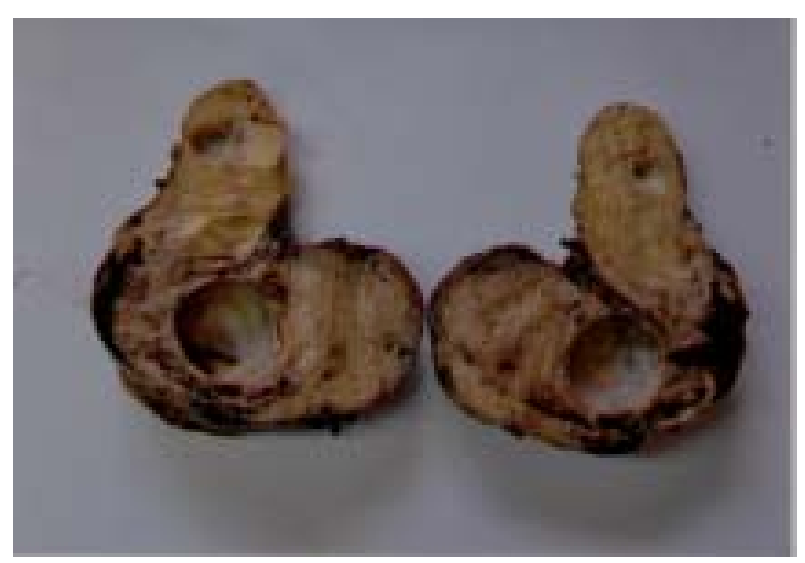

Figure 1. Computerised tomography showing the tumour with cystic and solid areas.
The tumour excision with coccygiectomy was done under general anaesthesia at the age of fourteen days and the postoperative course was uneventful.

Macroscopic appearance of the tumour showed an encapsulated, "L" shaped firm mass. The cut section predominantly showed fleshy, solid areas and four cysts measuring $2.5 \mathrm{~cm}, 1.0 \mathrm{~cm}, 0.8 \mathrm{~cm}$ and $0.6 \mathrm{~cm}$ in diameter respectively. Figure 2 shows a cut section of the tumour showing cystic and solid areas. The fluid inside the cysts was clear and brown in the two larger cysts and colourless in the two smaller cysts.

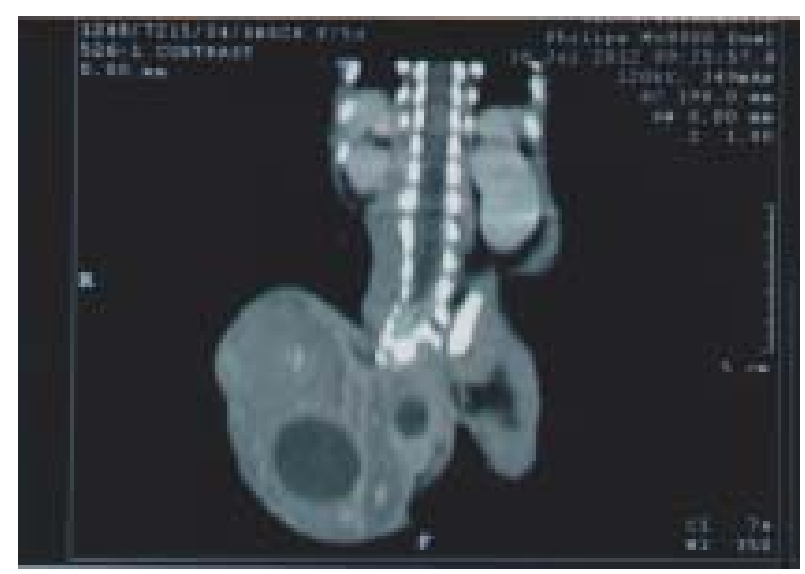

Figure 2. Cut section of the tumour showing cystic and solid areas.

Microscopy found sections of the solid areas showing disorderly but otherwise mature brain tissue, including neurons (Figure 3A). The neural lineage of the tissue was confirmed by positive staining for neuron specific enolase (Figure 3B). The lining of the cysts stained positively with glial fibrillary acidic protein and negatively with cytokeratin, confirming they were ependymal cells (Figure 3C). Extensive sections did not reveal any other type of tissue. The appearances were consistent with those of a hamartomatous lesion comprising of heterotopic brain tissue. A repeat alpha fetoprotein level six months after surgery was $12.1 \mathrm{ng} / \mathrm{ml}$ (normal range 1-130 ng/ml).

${ }^{1}$ Department of Pathology, Faculty of Medicine, Peradeniya, ${ }^{2}$ Surgical Unit and ${ }^{3}$ Radiology Unit, Sirimavo Bandaranaike Specialized Children's Hospital, Peradeniya, Sri Lanka.

Correspondence: WDPS, e-mail: < dammikawdps@gmail.com>. Received 16 January 2013 and revised version accepted 16 March 2013. Competing interests: none declared 


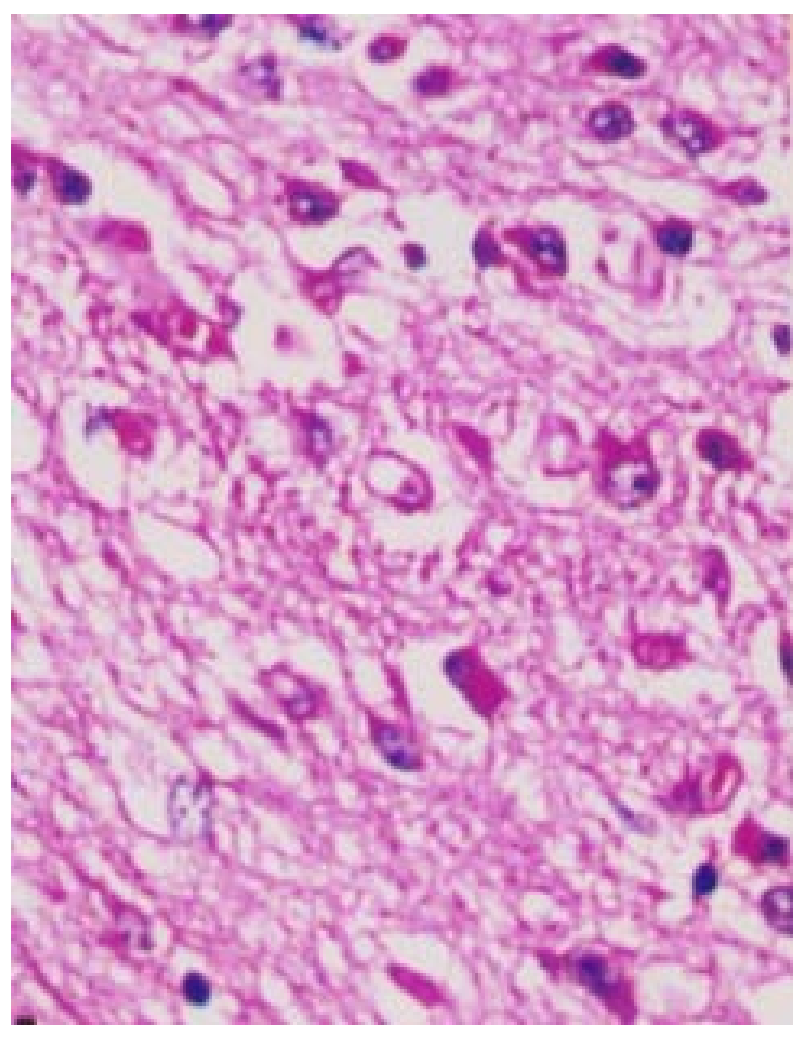

Figure $3 a$. Areas showing mature brain tissue. (Hematoxylin and Eosin x 400).

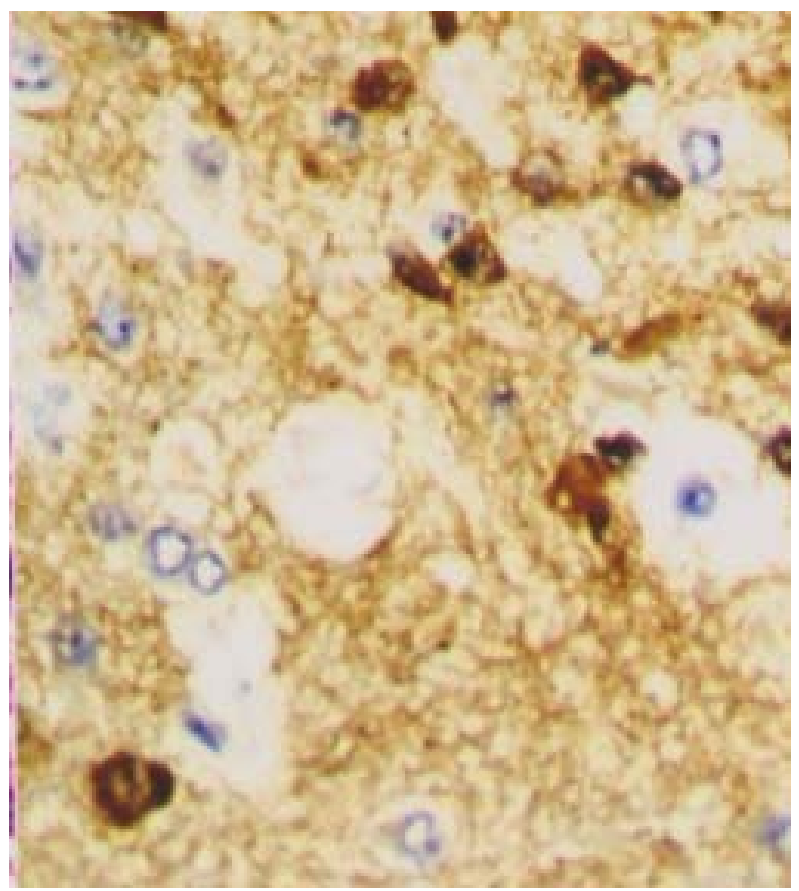

Figure 3b. Areas of brain tissue showing positivity for neuron specific enolase confirming the neural lineage of the cells. (Dako monoclonal mouse antihuman neurone specific enolase M-0873 $\times$ 400).

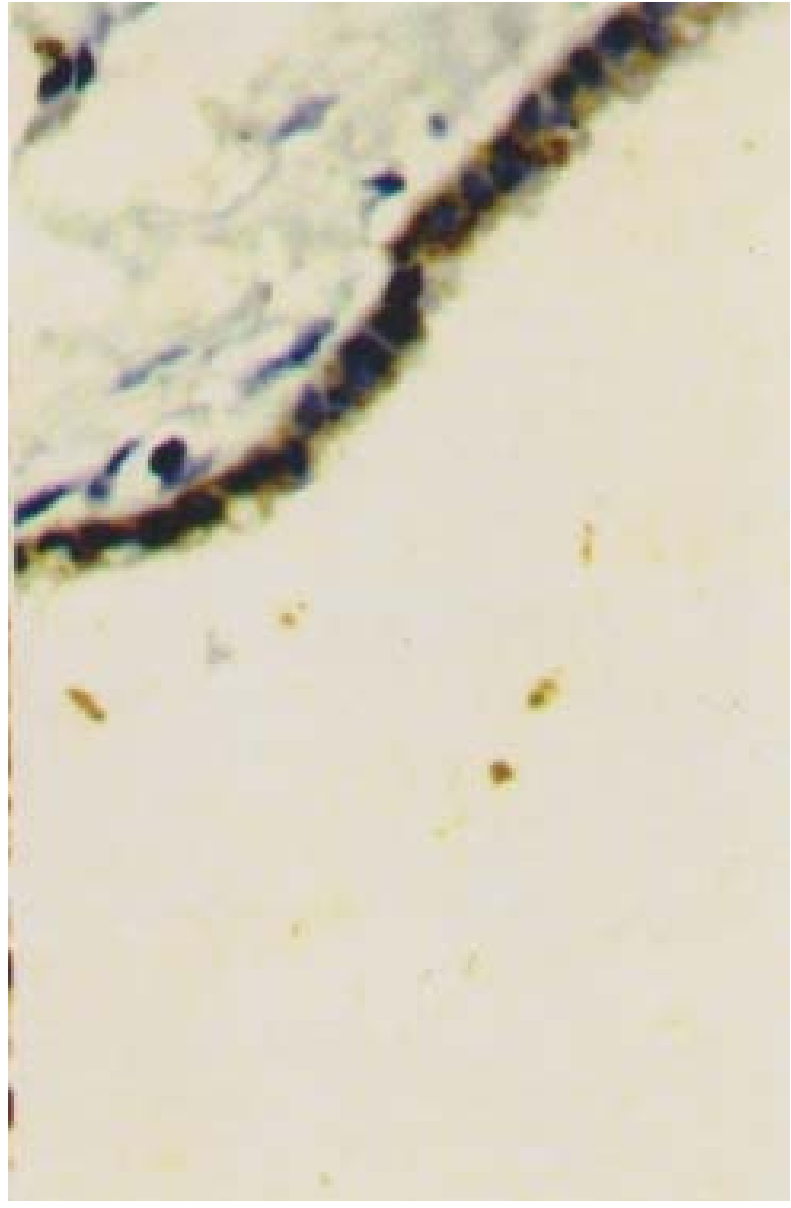

Figure 3c. Cyst lined by monoclonal cuboidal cells showing positivity for glial fibrillry acidic protein. (Monoclonal mouse antihuman glial fibrillary acidic protein Dako M-0761 x 400).

\section{Discussion}

Skin covered masses in the sacrococcygeal region include tumours, malformations and inflammatory conditions. Teratoma, hamartomatous lesions, subcutaneous or lumbosacral lipomata, neuroblastoma, ganglioneuroma, myxopapillary ependymoma and neurofibroma are examples of the tumours. Malformations such as meningiomyelocele, diastematomyelia, pilonidal sinus, sacral anomalies and other bone malformations make the diagnosis difficult in some cases. Perirectal abscesses are an example of the inflammatory conditions that presents as a skin covered mass in the sacrococcygeal region. Therefore, the diagnosis has to be made by a combination of an accurate history, physical examination, ultrasound scanning, X-ray radiology, computerised tomography, magnetic resonance imaging and histological assessment.

Sacrococcygeal teratoma (SCT) is one of the most common tumours in newborns and it is the commonest tumour involving the sacrococcygeal region [1-3]. The tumour in this neonate consisted only of mature brain tissue, and did not contain tissue derived from all three 
germ layers. Therefore, the diagnosis of sacrococcygeal teratoma was not possible.

A meningomyelocele, one of the differential diagnoses of sacrococcygeal masses, should also be considered here. It is usually covered by a membrane or is partialy covered by the skin. A posterior sacral meningomyelocele may be differentiated from sacrococcygeal teratoma by the change in tension occurring with crying, bulging of the fontanelle when manual pressure is applied over the mass, its more cephalad position, the spinal bony defect and the lack of attachment to the coccyx. Anterior sacral meningomyeloceles present as a presacral mass and are easily demonstrated by computerised tomography with myelogram or magnetic resonance imaging. Furthermore, in meningomyelocele, there are usually neurological defects in the legs. This baby girl did not show a weakness in the lower extremities. None of the other features were present in this baby girl.

A lipoma of cauda equina or filum terminale is easily recognisable histologically and it may be associated with a sacral spinal defect and a capillary haemangioma in the overlying skin. The possibility of cutaneous sinuses like pilonoidal sinuses can be easily excluded in this case, as the overlying skin did not show orifices of sinus tracts. Angiomas, perirectal abscesses and chordomas are uncommon and can be differentiated easily with histology. Therefore, the most likely diagnosis in this case is a hamartoma consisting heterotopic brain tissue in the sacrococcygeal region.

In neonates, the alpha fetoprotein serum levels are highly elevated (term neonates: 41,687 ng/ml, preterm neonates: 158,125 ng/ml) [4,5]. The alpha fetoprotein level of this baby at birth was within the normal range and it cannot be defined as a teratoma. Also yolk sac elements which produce the alpha fetoprotein in teratomas were not present in this tumour. These features further support the absence of a teratoma in this case. In most infants, the alpha fetoprotein levels decrease to normal adult levels within the first 10 months [4,5]. The repeated level six months after the surgery in this patient was normal.

\section{Acknowledgements}

We thank Prof. C. D. M. Fletcher of the Harvard Medical School, USA for his advice. The technical assistance of Mrs. H. M. N. B. Herath and Mrs. S. M. Wickramasinghe in the Department of Pathology, Faculty of Medicine, University of Peradeniya, Sri Lanka is also appreciated.

\section{References}

1. Liu KK, Lee KH, Ku KW. Sacrococcygeal teratoma in children; A diagnostic challenge. Australian and New Zealand Journal of Surgery 1994; 64: 102-5.

2. Lemire RJ, Beckwith JB. Pathogenesis of congenital tumours and malformations of the sacrococcygeal region. Teratology 1982; 25: 201-13.

3. Khanna S, Arya NC, Singhal GD. Sacrococcygeal tumours in children. Journal of Postgraduate Medicine 1987; 33: 109-14.

4. Schneider DT, Calaminus G, Gobel U. Diagnostic value of alpha/fetoprotein and beta-human chorionic gonadotropin in infancy and childhood. Pediatric Hematology and Oncology 2001; 18: 11-26.

5. Çorapçıoglu F, Türker G, Aydogan A, Sarper N, Duman C, Arısoy AE. Serum alpha fetoprotein levels in healthy fullterm neonates and infants. Marmara Medical Journal 2004; 17: 1-7.

\title{
Amyloidosis associated with HIV infection
}

\author{
W K M G Amarawardena, A Wijesundere, H A D Manohari
}

Ceylon Medical Journal 2013; 58: 128-129

\section{Introduction}

HIV/AIDS is a multi system disease, often associated with a variety of chronic inflammatory and infective diseases of varying aetiology. Amyloidosis is a disorder of protein metabolism characterised by extracellular deposition of pathological insoluble fibrillar proteins in organs and tissues [1]. We report a patient with amyloidosis associated with AIDS.

\section{General Hospital, Sri Jayawardenapura, Sri Lanka.}

Correspondence: WKMGA, e-mail: <maheshiamarawardena@gmail.com>. Received 2 November 2012 and revised version accepted 15 December 2012. Competing interests: none declared. 